\title{
INTRODUCCIÓN DOSSIER "MEMORIAS DE LA REPRESIÓN EN AMÉRICA LATINA"
}

A pesar de los intentos de negar y borrar la magnitud de los crímenes cometidos, la principal consecuencia de las dictaduras militares latinoamericanas fue paradójicamente la activación de una memoria social (Vezzetti, 2004). La importancia que la memoria ha adquirido en el espacio social se expresa no sólo en el surgimiento de un nucvo actor enrolado en la defensa de los Derechos humanos, en el fortalecimiento de los debates en torno a las causas y responsabilidades por la violencia represiva o en la demanda de juicio y castigo a los culpables, sino también en la institucionalización del recuerdo por parte del Estado -a través de monumentos, museos, memoriales y archivos-, en el fortalecimiento de un campo de producción artística c intelectual o en cl cada vez mas influyente papel de la educación y de los medios de comunicación en la transmisión de la memoria o del olvido.

Por una parte, la memoria colectiva sobre las dictaduras en América Latina se inserta en un marco de recuperación que, anclado en cl presente, involucra a varios actores sociales, quienes se entreveran, a su vez, en luchas y disputas por los sentidos y representaciones sobre cl pasado reciente. El Estado, las víctimas, los organismos de Derechos Humanos, las Fuerzas Armadas, la justicia nacional e internacional, los medios de comunicación, los intelectuales y artistas, las organizaciones armadas y sus militantes, los partidos políticos y la sociedad civil componen esta trama compleja de actores sociales, cuyas disputas se despliegan en diversos ámbitos de la vida social: la política, la cultura, el derecho, la historia, la familia, la ideología y la biografía personal.

Por otra parte, las mudanzas de contextos socio-políticos, la aparición de nuevos actores sociales, el surgimiento de relatos y testimonios desconocidos, los cambios en la sensibilidad social, el recambio generacional 
y las transformaciones en el escenario judicial influyen en la configuración y en la dinámica de las memorias nacionales sobre la represión (Jelin, 2002). Esta dinámica conforma a su vez contextos sociales de escucha colectiva, en los que algunas narraciones y voces - las de las víctimas, las de los militantes, las de las nuevas generaciones- encuentran o no un espacio de social de circulación y recepción. En tal sentido, lo dicho públicamente por aquellos que recuerdan y evocan el pasado convive con los rumores del silencio, con lo no-dicho, con lo que carece de condiciones colectivas de cscucha, pero que sin embargo se mantiene latente en los laberintos del recuerdo colectivo.

Ahora bien, si la memoria colectiva es una práctica en la que la experiencia del pasado colectivamente construida puede ser percibida como un hecho objetivo, estudiarla implica desentrañar los sentidos y relaciones que conforman esta objetividad. En tal sentido, abordar cuestiones relativas a la memoria, lleva a indagar en sus continuidades y rupturas, pero también por sus dinámicas y transformaciones, por sus disputas y tensiones y por sus planos y segmentaciones. A pesar de los procesos de objetivación y cristalización de la memoria en hábitos y narraciones o en una memoria oficial, es dificil concebirla como una totalidad cerrada y autocentrada. De modo tal que los artículos que aquí se reúnen buscan dar cuenta cómo la memoria colectiva sobre el pasado reciente es un proceso de construcción, en lucha no sólo contra la olvido sino también entre diversas memorias, sujetas a los relevos generacionales, influidas por coyunturas histórico-políticas y diferenciadas scgún niveles subjetivos y sociales, nacionales y grupales, institucionales y políticos.

El presente Dossier sobre "Memorias de la Represión en América Latina" se propone mostrar cómo cada sociedad nacional vive a su manera, en función de su historia y de sus problemas específicos estas diversas coyunturas memoriales. La conciencia de ser parte de una sociedad que comparte un pasado autoritario, permanece presente en el tiempo - a pesar de los intentos de borrarlo- y se acompaña no sólo con la pregunta por cómo ha sido esto posible sino también con el malestar de que semejante experiencia, por el sólo hecho de haberse producido una vez, podría volver a repetirse (Groppo, 2001). Afrontar colectivamente este pasado de violencia pucde implicar reconocerlo en sus aspectos más dolorosos y ser asumido, es decir, reconocido como propio, o por el contrario, olvidarlo, ocultarlo o disimularlo

Temáticas, Campinas, 17(33/34): 7-12, jan./jun. 2009 
para, de este modo, no afrontar ni aclarar las responsabilidades políticas y jurídicas. En el deseo o en el rechazo de recordar tal pasado autoritario se pone en juego la resistencia del crimen en la memoria pero también la evidencia del apoyo, la complicidad o el silencio de la población. Para varias generaciones, abrir los ojos al pasado implica hacer memoria sobre la propia responsabilidad, es decir, en qué medida cada uno ha contribuido con su comportamiento individual a hacer posibles la catástrofe y el horror. En este sentido es que la memoria colectiva sobre la represión puede ser entendida no sólo como el acto de rememoración del pasado sino también como la cristalización de un modo acrítico de recordarlo. Esta tensión entre recordar y reconocerse como parte de ese pasado marca los límites entre los cuales es posible pensar las relaciones que cada sociedad restablece con la violencia de su historia, especialmente con el Terrorismo de Estado.

Desde una perspectiva que permita comparar diferentes experiencias nacionales, este dossier se propone abordar la problemática de las memorias de la represión en América Latina a partir de diversas miradas disciplinarias historia, ciencia política, sociología, antropología-. Lo que incluye también una reflexión sobre algunos problemas teóricos y epistemológicos que se presentan en cl cstudio del pasado reciente a la hora de desarrollar la práctica investigativa y la producción de conocimiento. De alli que, en la indagación sobre el pasado reciente, la auto-reflexión crítica del investigador sobre su propia posición, sus origenes y sus intereses resulta imperiosa (Gagnebin, 2000, p. 100) El posicionamiento teórico de quién toma la palabra incide de múltiples formas sobre sus enunciados. Estos enunciados no son ni neutros ni inocentes y deben ser reflexionados juntamente con su enunciación, pues estas contribuciones inciden en los acontecimientos con el poder de su propia palabra. Por cllo, cl abordaje de la cuestión de la violencia exige la interrogación por parte del investigador de su propia responsabilidad simultáneamente científica e histórico-social.

Pues bien, este dossier reúne cinco artículos que desde diversas perspectivas teóricas y ámbitos disciplinarios se ocupan de las memorias de la represión en Brasil, Uruguay y Argentina. Asimismo tiene el propósito de reflejar los debates y reflexiones que atraviesan un campo de investigación que tiene que reflexionar no sólo sobre sus propias condiciones de producción 
sino que tiene que dialogar con las cuestiones teóricas y problemas éticas que implican el abordaje de la violencia.

El primer artículo, “iEsta es la Verdad!: construcción, sentidos y usos de la "verdad" en los informes "Nunca Más" del Cono Sur" de Aldo Marchesi, indaga, desde una perspectiva comparativa, no sólo los sentidos que adquirió la noción de verdad en los informes "Nunca Mas" sino también en el impacto que tuvieron en los procesos de democratización de Argentina, Uruguay, Brasil y Chile. En tal sentido, Marchesi muestra las limitaciones institucionales que las democracias nacientes sufrieron a la hora de reparar los crímenes cometidos por el Estado en el período previo y analiza los diversos tipos de repuestas que se produjeron cuando fue el Estado el que promovió los informes como en Argentina y Chile o cuando fuc la sociedad civil quien lo hizo como en Brasil y Uruguay.

Abordando el contexto histórico de la transición democrática, el artículo de Magdalena Broquetas San Martín "Pacificación, olvido y perdón en la inmediata post-dictadura en Uruguay (1985-1986)" indaga en los debates en torno a la promulgación de las leyes de amnistía y conmutación de penas para los presos políticos (marzo de 1985) y de caducidad de la pretensión punitiva del Estado (diciembre de 1986). Broquetas San Martín se centra en las nociones de "pacificación", "reconciliación", "olvido"y "perdón" que no sólo alimentaron los debates políticos y simbólicos en torno a la aprobación de ambas leyes sino que también propiciaron determinas interpretaciones y justificaciones sobre la violencia del pasado reciente uruguayo.

El artículo de Lucía Brienza, "Relatos en pugna sobre el pasado reciente en Argentina: las visiones militares sobre los años setenta desde Alfonsin hasta el primer gobierno de Menem (1983 - 1995)", se ocupa de las interpretaciones sobre el pasado represivo de las cúpulas militares desde la recuperación democrática en 1983 hasta la mensaje institucional del Jefe del Ejército Martín Balza en 1995 en Argentina. Brienza analiza las lógicas internas de las explicaciones militares sobre la represión, cuyo núcleo argumentativo, a pesar de sus reconfiguraciones, avala el accionar represivo. En este sentido es que el artículo describe a la memoria militar como una memoria replegada que se mantiene viva al interior de los círculos militares pero que se despliega 
profusamente en la esfera pública cuando el accionar de la justicia trac como consecuencia una sensación de amenaza a los integrantes de las fuerzas.

A partir del análisis de las leyes y textos constitucionales que rigen el acceso a los llamados "archivos de la dictadura" en Brasil, el trabajo "Os arquivos da ditadura: entre os direitos humanos e a segurança nacional" de Michel Goulart da Silva, demuestra que los 20 años de dictadura militar representan un incómodo pasado aún presente. Silva muestra cómo los documentos hoy disponibles tanto para los propios familiares como para investigadores son el resultado de años de lucha de los familiares de muertos y desaparecidos y del grupo Tortura Nunca Mais contra un Estado que limita su accesibilidad, negando la información que puede comprometer a los represores aún impunes, en función de criterios de seguridad nacional.

Por último, la significación del uso de testimonio en la compresión de la violencia política es la problemática que aborda el trabajo de Alejandra Oberti, "Lo que queda de la violencia política. Acerca de archivos y testimonios". A partir del análisis del lugar que ocupan los relatos personales en la construcción de la memoria y la historia del pasado reciente argentino, Oberti profundiza en los puntos centrales del debate teórico sobre sus potencialidades y limitaciones. Para ello, polemiza con los planteos desarrollados por Beatriz Sarlo en su libro Tiempo pasado. Cultura de la memoria y giro subjetivo y, de la mano de autores como Ricoeur y Agamben, propone que la multiplicación de narraciones testimoniales sobre los años setenta constituyc un elemento indispensable en la reconstrucción crítica de la experiencia del pasado reciente.

VALENTINA SALVI (ORG)

\section{BIBLIOGRAFIA}

GAGNEBIN, J. M. Palavras para Hurbinek. En NESTROVSKI, A. y SELIGMAN-SILVA, M. (org) Catástrofe e Representação. Ed. Escuta: São Pablo, 2000.

GROPPO, B. Traumatismos de la memoria e imposibilidad de olvido en los países del Cono Sur. En GROPPO, B. y FLIER, P. (comp.) La imposibilidad 
del olvido. Recorridos de la memoria en Argentina, Chile y Uruguay. Ediciones al Margen: La Plata, 2001.

JELIN, E. Los trabajos de la memoria. Siglo XIX: Buenos Aires-Madrid, 2002. VEZZE'TTI, H. Conflictos de la memoria en la Argentina. En Lucha Armada en la Argentina, Año 1, Nº1, Buenos Aires, 2004. 